International

Medical Society

http://imedicalsociety.org

\title{
Effects of Andiroba Oil (Carapa Guianensis) on Wound Healing in Alloxan-Diabetic Rats*
}

\begin{abstract}
Bruna Angelina Alves de Souza1, Leandro Augusto Braga1, Luiz Renato Oliveira Lopes ${ }^{1}$, Rubens Fernando Gonçalves Ribeiro Junior", Laiane Nazaré Silva do Nascimento ${ }^{3}$, Lainy Carollyne da Costa Cavalcante ${ }^{4}$, Andrew Moraes Monteiro ${ }^{5}$, Rodrigo Paracampo Couteiro ${ }^{5}$, Edson Yuzur Yasojima ${ }^{6}$, Moisés Hamoy ${ }^{6}$
\end{abstract}

\section{Abstract}

Purpose: To evaluate wound healing in diabetic rats by using topic Andiroba oil (Carapa guianensis).

Methods: Six male, adult, Wistar rats were distributed into three groups: Sham group (wound treatment with distilled water); Collagenase group (treatment with collagenase ointment); and Andiroba group (wound treatment with Andiroba oil). The wound was evaluated considering the macroscopic and microscopic parameters.

Results: The results indicated differences in the healing of incisional wounds between treatments when compared to control group. Accelerated wound healing was observed in the group treated with Andiroba oil and Collagenase in comparison to control group, especially after the $14^{\text {th }}$ day. Morphometric data confirmed the structural findings.

Conclusion: There was significant effect in topical application of Andiroba oil on wound healing in rats with induced diabetes.
1 Graduate Medical Student, UFPA, Belém-PA, Brazil.

2 Master in Surgery and Experimental Research (CIPE), UEPA, Belém, Pará, Brazil.

3 Graduate Biomedical Student, University Center of Pará State (CESUPA), Belém-PA, Brazil.

4 Graduate Medical Student, University Center of Pará State (CESUPA), BelémPA, Brazil.

5 Graduate Medical Student, State University of Pará (UEPA), Belém-PA, Brazil.

6 PhD, Full Professor, Medical School, Federal University of Pará (UFPA), Belém, Pará, Brazil.

*: Research performed at Laboratory of Pharmacology and Toxicology of Natural Products. Federal University of Pará (UFPA), Belém, PA, Brazil.

Contact information:

Rubens Fernando Gonçalves Ribeiro Júnior.

Address: Marquês de Herval Av. 1823. Pedreira. 66087-320. Belém-PA, Brazil.

” rubensfernandojr@gmail.com 


\section{Introduction}

Diabetes mellitus (DM) is the chronic metabolic disease that determines hyperglycemia state that causes damage to blood vessels, heart, eyes, kidneys and nerves. Between feared complications is diabetic foot that includes vascular and osteoarticular alterations that promotes to formation of ulcers, especially in the lower limbs [1].

The hyperglycemic state of DM also determines a state of poor healing where these ulcers can evolve with necrosis and amputation of the lower limb. To avoid such an outcome, alternatives are sought to improve this healing and medicinal plants with their various properties being discovered may be effective with the advantage of lower cost compared to the standard treatment of diabetic foot ulcers $[2,3]$.

Already described with this great potential, Andiroba oil (Carapa guianensis), is used in popular culture with healing purpose. Research has shown that the use of oil effectively participates in wound healing promoting the formation of granulation tissue, tissue contraction and epithelialization [4, 5].

\section{Methods}

Six (15-20 weeks) male Wistar rats (Rattus norvegicus) weighting 250-350g were used in this study. The animals were kept in a vivarium of Federal University of Pará (UFPA) with a controlled temperature, light, humidity, and noise; water and food was provided ad libitum. The project was previously approved by the Animal Use and Care Committee of Federal University of Pará (Protocol n 1215270916) and followed the rules of Brazilian National Law for Animal Care (Law: 11.794/08).

\section{Experimental protocol}

Three groups of study comprised this study:

- Control Group (CG): distilled water were applied everyday and once in a day until euthanasia, a volume of $0.3 \mathrm{ml} .(\mathrm{N}=2)$
- Collagenase Group (CLG): collagenase ointment (0.6 U/g) were applied everyday and once in a day, a volume of $0.3 \mathrm{ml}$ until euthanasia. $(\mathrm{N}=2)$

- Andiroba Group (RG): Andiroba oil were applied everyday and once in a day until euthanasia, a volume of $0.3 \mathrm{ml}$. ( $\mathrm{N}=2)$

Animals were then randomly assigned into three subgroups: seven, 14 and 21 days, according to euthanasia with anesthetic overdose.

\section{Induction of diabetes in experimental animals}

Rats were injected intraperitoneally with a freshly prepared solution of alloxan monohydrate dissolved in a normal saline solution of $\mathrm{NaCl} 0.9 \% \mathrm{pH}$ 4 at a dose of $150 \mathrm{mg} / \mathrm{kg}$ [6]. This injection can provoke fatal hypoglycemia as a result of reactive massive release of pancreatic insulin, rats were also given orally $5-10 \mathrm{ml}$ of a $20 \%$ glucose solution after $6 \mathrm{~h}$. Rats were then kept for the next $24 \mathrm{~h}$ on a $5 \%$ glucose solution as beverage to prevent too severe hypoglycemia [7]. After 2 weeks, rats displaying glycosuria and hyperglycemia (blood glucose levels $2 \mathrm{~g} / \mathrm{l}$ ) were retained for the experiments.

\section{Surgical procedures}

Dorsal region was shaved and then antisepsis of region was done. Next, three interscapular wounds of $5 \mathrm{~mm}$ of diameter was made in skin by caudocranial direction with a metallic punch, the distance between them were $5 \mathrm{~mm}$ (Figure 1). During postoperative days, animals remained in individual cages and isolated from their bedding through a metallic net to avoid wound infection. The rats were euthanized by anesthetic overdose.

\section{Macroscopic analysis}

To determine the largest diameter of the wound and its macroscopic used a magnifying glass with $2.5 \mathrm{x}$. The wound was measured with a pachymeter graduated in millimeters and area was calculated with Image ${ }^{\circledR}$ software. 
Figure 1: Representation of wounds according to groups.

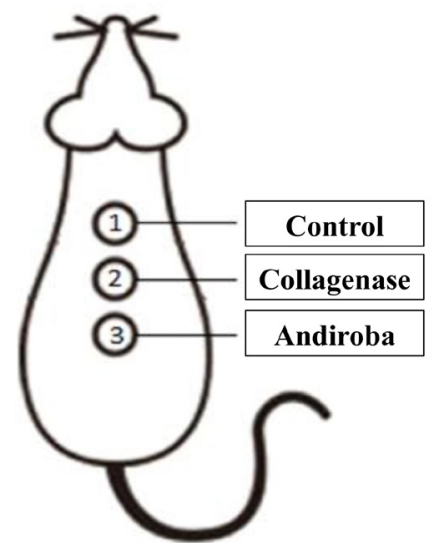

Source: Research protocol.

\section{Histological analysis}

After euthanasia, wounds were harvested, fixed in $10 \%$ formaldehyde, embedded in paraffin, stained using Hematoxyline-Eosine and Masson's trichrome. In stained tissues, multiple sections were analyzed with regard to the presence of re-epithelialization, intensity of local inflammatory reaction, type of inflammatory response as the predominant cell, the presence of granulation tissue, neovascularization and fibrosis [8].

\section{Statistics}

Analysis of variance (ANOVA), followed by Tukey posthoc test correction, was performed for the ma- croscopic analysis and proportion of collagen fibers. Kruskal-Wallis test was used for the histological parameters. Statistical significance was assumed at $p<0.05$.

\section{Results}

No significant differences in age and body weight of the animals were found between the study before and after the intervention.

\section{Macroscopic results}

Comparing the groups according to the time of measurement, a statistical difference was observed between Collagenase and Andiroba with Control group in $7^{\text {th }}, 14^{\text {th }}$ and $21^{\text {st }}$ day. It was also found a difference between Andiroba oil with Collagenase group in $7^{\text {th }}$ and $14^{\text {th }}$ day (Table 1 and Figure 2 ).

Table 1. Mean \pm SD of wound area within days according to groups.

\begin{tabular}{|c|c|c|c|c|}
\hline & \multicolumn{3}{|c|}{ Mean of wound area $\left(\mathrm{mm}^{2}\right)$} & \multirow{2}{*}{$\mathrm{p}$-value } \\
\hline & Control & Collagenase & Andiroba & \\
\hline $7^{\text {th }}$ Day & $0.49 \pm 0.01$ & $0.47 \pm 0.01^{a}$ & $0.40 \pm 0.01^{a, b}$ & 0.006 \\
\hline $14^{\text {th }}$ Day & $0.33 \pm 0.02$ & $0.27 \pm 0.01^{a}$ & $0.30 \pm 0.02^{a, b}$ & 0.005 \\
\hline $21^{\text {st }}$ day & $0.13 \pm 0.01$ & $0.0 \pm 0.0^{a}$ & $0.0 \pm 0.0^{a}$ & 0.003 \\
\hline
\end{tabular}

Figure 2: Morphometric analysis of wound area.

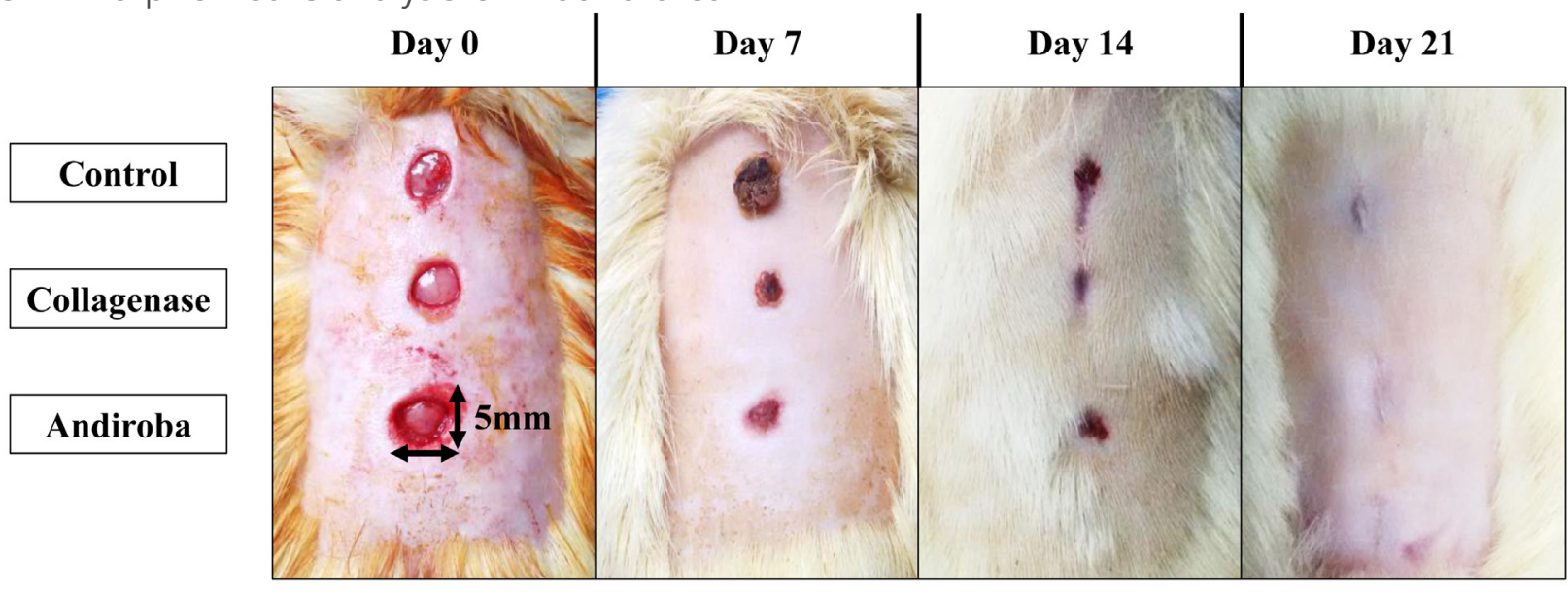




\section{Microscopic results}

There was no statistical difference between the groups at different times regarding the degree of re-epithelialization and the presence of granulation tissue. However, predominance of chronic response type was noted in the groups at all wound evaluation times and was observed statistical difference regarding the intensity of the local inflammatory response with predominance of monomorphonuclear infiltrate at different times of collagenase and Andiroba oil when compared to the control group ( $p=0.0389$ and $p=0.0475$, respectively).

\section{Discussion}

Several substances have been tested in wound healing process. However, the results are not always satisfactory when compared to the control group or even active compounds may slow the overall wound healing. Therefore, the study of wound healing becomes of great value for scientific knowledge.

Throughout the experimental part of this article, all animals evolved well postoperatively, be it 7, 14 or 21 days without causing infection, death or replacement of animals to the study, proving that this model of incisional wound induction was efficient.

Proteolytic enzymes have been used in wound healing for many years and the most commonly used enzymes are fibrinolysin/DNAse and collagenase [9-11], where collagenases act by degrading native helical collagen fibrils [12]. Recently, Tallis et al. (2013) showed that the collagenase ointment is tolerable and clinically effective in providing nonviable tissue removal and allow effective scar [13].

There was a significant difference in collagenase with control group on days 7, 14 and 21, which demonstrates its mechanism of action, especially in the acute phase of incisional wound healing.

However, Andiroba oil showed surprising results compared to the control group, obtaining a lower average of the wound area when compared to control group. Mainly in the macroscopy where a degree of almost total contraction of the incisional wound was observed on 21 day.

Researchers have showed the anti-inflammatory properties of tetraterpenoids and limnoids isolated respectively from C. guianensis [14]. However, phytochemical analysis of Andiroba by qualitative analysis showed the presence of alkaloids, saponins, tannins and essential oils and absence of other constituents like triterpenoids and flavonoids. Possibly, constituents like tannins, saponins and alkaloids may play a role in the process of wound healing, however, further phytochemical studies are needed to isolate the active compound(s) responsible for these pharmacological activities.

Anti-inflammatory effects of C. guianensis are attributed to its possible antihistaminergic activity, the antioxidant activity of C. guianensis cannot be discounted. Like honey which is known to have anti-inflammatory, wound-healing promoting action [15] and antibacterial activity [16], C. guianensis may also have anti-inflammatory, immunostimulant and pro-healing properties. As C. guianensis did not inhibit the growth of microorganisms associated with wound infections, its wound-healing promoting activity is independent of its antimicrobial activity

Essential fatty acids are required for many physiological processes as present in Andiroba oil, such as maintaining the integrity of the skin and the structure of cell membranes and the synthesis of biologically active compounds. Among the health benefits attributed to fatty acids are: anticarcinogenesis, antiatherosclerosis, inhibition of free radicals, alteration in the composition and metabolism of adipose tissue, immunomodulation, antibacterial and antidiabetic activity [17].

The essential fatty acids also have a structural function, forming part of the phospholipids of the cellular membranes of the tissues of the organism, being the precursors of prostaglandins and leukotrienes from the synthesis of arachidonic acid [17, 
18]. Already phospholipids involved in various metabolic processes, such as the active phosphorylation process in mitosis and cell organization and ion exchange, which gives the Andiroba oil a high potential in the treatment of wound healing [19].

We must consider that human skin differs from rat and the important difference is that human skin cures preferentially by re-epithelialization, whereas the skin of the rat heal mainly by contraction of the wound [20]. We also recognize the limitations for translational relevance of our experimental study. However, skin lesions in animal models are relevant because they provide significant contributions to advances in the treatment of incisional wounds.

The experimental model demonstrated greater efficacy of topical application of Andiroba oil in tissue formation, epithelialization, angiogenesis and collagen deposition in skin lesion compared to the Control group.

\section{Conclusion}

Andiroba oil is able to reduce intensity of inflammatory response of the wound, maintaining the same type of inflammatory response when compared to the collagenase group, proven by macroscopic results, in which there was a greater retraction of wound in animals treated with Andiroba oil and no evidence of incisional wound healing impaired.

\section{Conflict of Interest}

None

\section{Financial Sources}

PIBIC-UFPA.

\section{References}

1. Domingueti $C P$, Dusse LM, Carvalho MD, de Sousa LP, Gomes $K B$, Fernandes AP. Diabetes mellitus: The linkage between oxidative stress, inflammation, hypercoagulability and vascular complications. J Diabetes Complications. 2016 May-Jun; 30(4):738-45. doi: 10.1016/j.jdiacomp.2015.12.018.
2. Lipsky BA, Aragón-Sánchez J, Diggle M, Embil J, Kono S, Lavery $L$ et al. IWGDF guidance on the diagnosis and management of foot infections in persons with diabetes. Diabetes Metab Res Rev. 2016 Jan; 32 Suppl 1:45-74. doi: 10.1002/dmrr.2699.

3. Powers JG, Higham C, Broussard K, Phillips TJ. Wound healing and treating wounds: Chronic wound care and management. J Am Acad Dermatol. 2016 Apr; 74(4):607-25. doi: 10.1016/j. jaad.2015.08.070.

4. Burlando B, Cornara L. Revisiting Amazonian Plants for Skin Care and Disease. Cosmetics 2017, 4(3), 25. doi:10.3390/ cosmetics4030025.

5. Higuchi K, Miyake T, Ohmori S, Tani Y, Minoura K, Kikuchi T et al. Carapanosins A-C from Seeds of Andiroba (Carapa guianensis, Meliaceae) and Their Effects on LPS-Activated NO Production. Molecules. 2017 Mar 22; 22(3). doi: 10.3390/ molecules22030502.

6. Ben Abdallah Kolsi R, Ben Gara A, Jardak N, Chaaben R, El Feki A, El Feki L et al. Inhibitory effects of Cymodocea nodosa sulphated polysaccharide on $\alpha$-amylase activity, liver-kidney toxicities and lipid profile disorders in diabetic rats. Arch Physiol Biochem. 2015; 121(5):218-27. doi: 10.3109/13813455.2015.1107588.

7. Gupta MP, Solis NG, Avella ME, Sanchez C. Hypoglycemic activity of Neurolaena lobata (L.) R. BR. J Ethnopharmacol. 1984 May; 10(3):323-7. doi: 10.1016/0378-8741(84)90020-5.

8. Santos LOM, Simões MLPB, Machado APB, Matioski FGR, Endo $P C$, Gruen GR, et al. Effect of somatotropin on skin wound healing in rats. Acta Cir. Bras. 2002 Jul-Aug; 17(4):220-224. doi: 10.1590/S0102-86502002000400004.

9. Peter FW, Li-Peuser $H$, Vogt PM, Muehlberger T, Homann $\mathrm{HH}$, Steinau HU. The effect of wound ointments on tissue microcirculation and leucocyte behaviour. Clin Exp Dermatol. 2002 Jan; 27(1):51-5. doi: 10.1046/j.0307-6938.2001.00937.x.

10. Marazzi M, Stefani A, Chiaratti A, Ordanini MN, Falcone L, Rapisarda V. Effect of enzymatic debridement with collagenase on acute and chronic hard-to-heal wounds. J Wound Care. 2006 May; 15(5):222-7. doi: 10.12968/jowc.2006.15.5.26910.

11. Ostlie DJ, Juang D, Aquayo P, Pettiford-Cunningham JP, Erkmann $E A$, Rash DE, et al. Topical silver sulfadiazine vs collagenase ointment for the treatment of partial thickness burns in children: a prospective randomized trial. J Pediatr Surg. 2012 Jun; 47(6):1204-7. doi: 10.1016/j.jpedsurg.2012.03.028.

12. Mekkes JR, Zeegelaar JE, Westerhof W. Quantitative and objective evaluation of wound debriding properties of collagenase and fibrinolysin/desoxyribonuclease in a necrotic ulcer animal model. Arch Dermatol Res. 1998 Mar; 290(3):1527. doi: $10.1007 / \mathrm{s} 004030050281$. 
13. Tallis A, Motley TA, Wunderlich RP, Dickerson Jr JE, Waycaster $C$, Slade $H B$, et al. Clinical and economic assessment of diabetic foot ulcer debridement with collagenase: results of a randomized controlled study. Clin Ther. 2013 Nov; 35(11):180520. doi: 10.1016/j.clinthera.2013.09.013.

14. Nayak BS, Vinutha B, Geetha B, Sudha B. Experimental evaluation of Pentas lanceolata flowers for wound healing activity in rats. Fitoterapia. 2005 Dec; 76(7-8):671-5. doi: 10.1016/j.fitote.2005.08.007.

15. Lusby PE, Coombes A, Wilkinson JM. Honey: a potent agent for wound healing? J Wound Ostomy Continence Nurs. 2002 Nov; 29(6):295-300. doi: 10.1067/mjw.2002.129073.

16. Simon A, Traynor K, Santos K, Blaser G, Bode U, Molan P. Medical honey for wound care-still the 'latest resort'? Evid Based Complement Alternat Med. 2009 Jun; 6(2):165-73. doi: 10.1093/ecam/nem175.

17. Funck LG, Barrera-Arellano D, Block JM. Conjugated Linoleic Acid (Cla) And Its Relationship With Cardiovascular Disease And Associated Risk Factors. Arch Latinoam Nutr. 2006; 56(2).

18. Pareja B. Dermopharmacy: medicinal plants with aplications in dermatology and cosmetics. Folia Dermat Peruana. 1996 7(3/4):48-52.

19. Godoy JMP, Prado PA. Ácidos gordos essenciais enriquecidos com vitamina $A, E$ e ácido linoleico como pensos em feridas crônicas. Rev Port Clin Geral. 2005 21:193-5.

20. Szentmihályi K, Vinkler $P$, Lakatos $B$, Illés $V$, Then $M$. Rose hip (Rosa canina L.) oil obtained from waste hip seeds by different extraction methods. Bioresour Technol. 2002 82(2): 195-201. doi: 10.1016/S0960-8524(01)00161-4.

Publish in International Archives of Medicine

International Archives of Medicine is an open access journal publishing articles encompassing all aspects of medical science and clinical practice. IAM is considered a megajournal with independent sections on all areas of medicine. IAM is a really international journal with authors and board members from all around the world. The journal is widely indexed and classified Q2 in category Medicine. 